\title{
Formulation and Pharmacokinetics of Ketorolac Tromethamine Floating Compression Coated Mini-Tablets
}

\section{Vemula SK ${ }^{1,3}$, Venisetty $\mathbf{R K}^{1}$ and Veerareddy $\mathbf{P R}^{1,2 *}$}

${ }^{1}$ Department of Pharmaceutics, Chaitanya College of Pharmacy Education and Research, Warangal, Telangana, India

${ }^{2}$ College of Pharmacy, Palamuru University, Mahabubnagar, Telangana, India

${ }^{3}$ Department of Pharmaceutics, MAK College of Pharmacy, Telangana, India

\begin{abstract}
Present research is intended to develop the Ketorolac Tromethamine (KTM) effervescent floating mini-tablets using compression coating method. Mini-tablets have the advantages of both tablets and multiparticulate formulations such as pellets. The main principle of floating mini-tablets can be applied to decrease the irritant effect of KTM on the stomach by avoiding the direct contact with the gastric mucosa and obtaining a low dosage for prolonged periods. KTM mini-tablets were prepared using $4 \mathrm{~mm}$ round flat punches and compression coated with hydroxypropyl methylcellulose and effervescent mixture. The prepared tablets were evaluated for weight variation, thickness, friability, hardness, drug content, in vitro buoyancy and in vitro release and the best formulation was subjected to further in vivo examination. The prepared mini-tablets exhibited satisfactory physicochemical characteristics. Formulation F3 offered the best controlled drug release $(99.46 \pm 0.93 \%$ in $12 \mathrm{~h}$ and T80\% $=9.4 \mathrm{~h})$ along with floating lag time $<30 \mathrm{~s}$ and total floating time $>12 \mathrm{~h}$. Pharmacokinetic studies of $\mathrm{F} 3$ formulation in male albino rabbits showed 2.25-fold higher bioavailability and 1.35-fold higher $\mathrm{C}_{\max }$ compared to immediate release core mini-tablets. Hence development of KTM effervescent compression-coated floating mini-tablets is the best way to give through oral route to maximize the therapy.
\end{abstract}

Keywords: Bioavailability; Compression-coating; Floating lag time; Floating mini-tablets; Pharmacokinetic studies

\section{Introduction}

Control and prolongation of gastric residence time is one of the key strategies to improve the absorption and bioavailability for dosage forms which remain in the stomach for a longer period of time. Gastroretentive drug delivery systems are such dosage forms that can reside in the gastric region for several hours. Extended gastric retention enhances bioavailability and improves solubility for drugs that are less soluble in high $\mathrm{pH}$ environment [1]. One of the simplest approaches to achieve the gastro retention is formulation of Floating Drug Delivery Systems (FDDS). FDDS are low density systems that include different effervescent components for floatation and some cellulose derivatives for controlled/sustained release. When FDDS come in contact with gastric content, carbon dioxide is released and is entrapped in the hydrocolloids which make the dosage forms to float and the drug is released slowly [2].

Multiple-unit systems (pellets or mini-tablets) act as prominent floating systems that avoid all or nothing emptying, less chance of localized mucosal damage. They also offer high predictable drug release kinetics and able to administrate as different release profile layers $[3,4]$. Development of mini-tablets is a significant alternative to pellets and other multiple-unit systems that show the following advantages like ease of manufacturing, packaging, storage and minimum scalability problems. Mini-tablets also exhibits equal dimensions and weight with smooth regular surface in a reproducible and continuous way unlike pellets [5]. Some of the research examples on mini-tablets of various delivery systems are flurbiprofen [6], ketorolac tromethamine [5], levofloxacin [7], theophylline [8], furosemide [9], ibuprofen [10] and diclofenac sodium [11].

Ketorolac Tromethamine (KTM) is a potent non-steroidal antiinflammatory drug with short biological half-life (4-6 h) and it is mainly absorbed in the proximal part of the small intestine [12]. KTM is 800 times more potent than aspirin and produces strongly analgesic and moderate anti-inflammatory activity [13]. The main principle of floating beads can be applied to decrease the irritant effect of KTM on the stomach by avoiding the direct contact with the gastric mucosa and obtaining a low dosage for prolonged periods [14,15]. The aim of the present work is to prepare KTM floating mini-tablets using hydroxypropyl methylcellulose (HPMC K15M) to control the drug release and sodium bicarbonate as a gas forming agent.

\section{Materials and Methods}

\section{Materials}

KTM was obtained from KP labs, Hyderabad, India. HPMC K15M belongs to Finar Chemicals Ltd, India. All other materials and solvents used were of analytical grade, purchased from SD Fine Chemicals India. Preparation of floating compression coated mini-tablets KTM core mini-tablets were prepared using wet granulation method. Accurately weighed amount of KTM and excipients other than glidant and lubricant passed through 60\# sieve and mixed in a poly bag for 5-10 min. The obtained uniform blend was converted in to granules using $10 \%$ starch paste, lubricated after drying and sieving and compressed into tablets on 8 station rotary tabletting machine using $4 \mathrm{~mm}$ round flat punches at $10 \mathrm{rpm}$ speed at $3000 \mathrm{~kg}$ compression force. Each minitablet contains $20 \mathrm{mg}$ drug and final weight was adjusted to $60 \mathrm{mg}$ (Table 1). Then the core tablets were compression coated with different compositions of coats given in using the procedure given in Veerareddy

*Corresponding author: Veerareddy PR, Department of Pharmaceutics, Chaitanya College of Pharmacy Education and Research, Kishanpura, Hanamkonda, Warangal, 506001, Telangana, India, Tel: +919704025402; E-mail: vpreddyindia@gmail.com

Received July 21, 2017; Accepted July 31, 2017; Published August 08, 2017

Citation: Vemula SK, Venisetty RK, Veerareddy PR (2017) Formulation and Pharmacokinetics of Ketorolac Tromethamine Floating Compression Coated MiniTablets. J Bioequiv Availab 9: 493-498. doi: 10.4172/jbb.1000351

Copyright: () 2017 Vemula SK, et al. This is an open-access article distributed under the terms of the Creative Commons Attribution License, which permits unrestricted use, distribution, and reproduction in any medium, provided the original author and source are credited. 
and Vemula, 2012 with $8 \mathrm{~mm}$ round, flat and plain punches at $5000 \mathrm{~kg}$ compression force [16].

\section{Determination of tabletting parameters}

To certify the tablet uniformity and mechanical integrity, the prepared tablets were evaluated for weight variation, hardness, friability and drug content. Using the standard procedures, the above parameters were determined [17]. Drug content uniformity was assessed by estimation of drug content in randomly picked ten tablets (drug powder equivalent to $100 \mathrm{mg}$ in $100 \mathrm{ml}$ of $0.1 \mathrm{~N} \mathrm{HCl}$ buffer) at $\lambda_{\max }$ of $322 \mathrm{~nm}$ using UV-Visible spectrophotometry. Floating lag time and total floating time were determined using the procedure described by Rosa et al. [18]. The tablets were also evaluated for the swelling behaviour by calculating the percentage swelling index using the standard procedure described by Tadros [19].

\section{In vitro dissolution studies}

In vitro dissolution studies were conducted using USP XXIV Type II dissolution apparatus (Electro lab, TDT-08L) in $0.1 \mathrm{~N} \mathrm{HCl}$ solution at $50 \mathrm{rpm}$ speed and $37 \pm 0.5^{\circ} \mathrm{C}$ temperature. $2 \mathrm{ml}$ samples were collected $(n=6)$ and restored the same level of fresh pre- warmed media at scheduled time intervals for $24 \mathrm{~h}$, filtered through $0.45 \mu \mathrm{m}$ membranes (Millipore, USA) and analyzed by HPLC method $[12,17]$. Then the dissolution data was interpreted to zero order, first order and Higuchi models and Koresmeyer-Peppas model [20] to elucidate the drug release mechanism. Also calculated the mean dissolution time, dissolution efficiency [21], T50\% and T80\% (time in hours to take $50 \%$ and $80 \%$ drug release) from above data to explain the drug release pattern.

\section{Stability studies}

Stability studies were conducted for F3 floating tablets using ICH guidelines i.e., stored at $40 \pm 2^{\circ} \mathrm{C}$ and $75 \pm 5 \% \mathrm{RH}$ in the humidity chamber for six months [22]. Then the collected samples were determined for assay and in vitro dissolution rate and statistically analysed using paired t-test at 0.05 significance level [23]. Then the similarity factor (f2) was calculated between dissolution rates of F3 tablets before and after storage Similarity factor is calculated to show the similarity between best formulation dissolution profile before and

\begin{tabular}{|l|c|}
\hline \multicolumn{1}{|c|}{ Ingredients } & Quantity (mg) \\
\hline KTM & 20 \\
\hline Avicel PH 102 & 35.2 \\
\hline Crosspovidone & 3 \\
\hline Starch paste (10\%) & Q.S $^{*}$ \\
\hline Talc & 1.2 \\
\hline Magnesium stearate & 0.6 \\
\hline Core weight & 60 \\
\hline
\end{tabular}

${ }^{*}$ Q.S: Quantity Sufficient

Table 1: Composition of KTM core mini-tablets. after storage. If similarity factor value will be above 50 , it indicates the similarity and if less than 50 they are non-similar.

$\mathrm{F} 2=50 \times \log \left\{\left[1+(1 / \mathrm{n}) \sum \mathrm{t}=\ln \left(\mathrm{R}_{\mathrm{t}}-\mathrm{T}_{\mathrm{t}}\right) 2\right]-0.5 \times 100\right\}$

\section{In vivo pharmacokinetics-study design}

In vivo pharmacokinetics studies were conducted in albino male rabbits weighing $2 \mathrm{~kg}$ after obtaining approval from the Institutional Animal Ethical Committee (IAEC/VCP/2015/6/2). The present study was designed to compare the KTM compression coated floating tablets with immediate release core mini-tablets using a two-way crossover design with 2 weeks of washout period. Male albino rabbits were divided into two groups $(n=6)$, in which group I animals were treated with immediate release core mini-tablets (20 $\mathrm{mg}$ dose) and group II with compression coated floating mini-tablets of same dose in the first phase whereas vice versa in second phase of study. Blood samples $(0.5$ $\mathrm{ml}$ ) were collected from marginal ear vein at $0.5,1,2,4,6,8,12,18$ and $24 \mathrm{~h}$ post oral dose in EDTA coated Eppendorf tubes. Plasma was separated by centrifuging at $4000 \mathrm{rpm}$ for $15 \mathrm{~min}$ and stored at $-20^{\circ} \mathrm{C}$ until analysis.

\section{HPLC analysis of KTM in plasma}

Plasma concentrations of KTM from above samples were determined by HPLC method adopted from Vemula et al. [12,17] with slight modifications. To $1 \mathrm{ml}$ of plasma sample $1 \mathrm{ml}$ of acetonitrile was added and centrifuged for $10 \mathrm{~min}$ at $3000 \mathrm{rpm}$ and the supernatant liquid was separated and filtered through $0.2 \mathrm{~m}$ filter and $20 \mathrm{ml}$ was injected in to the system. The analysis was carried out using Shimadzu HPLC (Shimadzu Corporation, Japan) equipped with C18 column and UV detector. The mobile phase consisted of acetonitrile and water (1:1). The eluents were examined at wavelength of $319 \mathrm{~nm}$ at a flow rate of $0.8 \mathrm{ml} / \mathrm{min}$.

\section{Pharmacokinetic analysis}

Required pharmacokinetic parameters were calculated using Kinetica software (Kineitca 2000 version 3.0, InnaPhase Corporation, 2000). Peak plasma concentration $\left(C_{\max }\right)$ and the time to reach peak plasma levels $\left(\mathrm{T}_{\max }\right)$ were attained directly from the time versus plasma concentration graph, the area under the curve (AUC) and the Area under First Moment Curve (AUMC) were estimated by trapezoidal rule and calculated the Mean Residence Time (MRT) and relative bioavailability [24]. Above pharmacokinetic parameters of both immediate release and floating tablets were subjected to statistical analyses using Analysis of Variance (ANOVA) and the difference less than the probability level 0.05 was considered statistically significant. In vitro cumulative percent of drug release of F3 tablets was compared against the cumulative AUC values of the same to demonstrate the in vitro-in vivo correlation (IVIVC) (Table 2).

\begin{tabular}{|c|c|c|c|c|c|}
\hline Formulation code ${ }^{*}$ & Core tablet (mg) & HPMC K15M (mg) & Sodium bicarbonate (mg) & Citric acid (mg) & Total tab weight (mg) \\
\hline $\mathrm{F} 1$ & 60 & 15 & 30 & 15 & 180 \\
\hline $\mathrm{F} 2$ & 60 & 30 & 30 & 15 & 180 \\
\hline F3 & 60 & 45 & 30 & 15 & 180 \\
\hline $\mathrm{F} 4$ & 60 & 60 & 30 & 15 & 180 \\
\hline F5 & 60 & 75 & 30 & 15 & 180 \\
\hline
\end{tabular}

${ }^{*}$ Each compression coat formulation contains 1\% Magnesium stearate, $2 \%$ Talc and Avicel PH 102 to make up the compression coat weight Table 2: Composition of KTM floating compression coated mini-tablets. 
Citation: Vemula SK, Venisetty RK, Veerareddy PR (2017) Formulation and Pharmacokinetics of Ketorolac Tromethamine Floating Compression Coated Mini-Tablets. J Bioequiv Availab 9: 493-498. doi: 10.4172/jbb.1000351

\section{Results}

\section{Evaluation of floating compression coated mini-tablets}

Table 3 showed all the evaluated physical parameters of prepared floating tablets. All the tablets were found to be uniform in the weight variation and drug content. The hardness and friability of tablets were found to be around $5 \mathrm{~kg} / \mathrm{cm}^{2}$ and below $0.5 \%$ respectively. The prepared floating tablets demonstrated adequate buoyancy ability and floated for more than $12 \mathrm{~h}$ in the dissolution medium. The floating lag time is found to be 26-37 sec, which is influenced by amount of effervescent mixture and the concentration of HPMC. From the swelling studies, the percentage water uptake of the floating tablets was found in the range of $78-116 \%$ (Table 4). F5 tablets have shown maximum swelling index due to high concentration of HPMC K15M.

\section{In vitro dissolution studies}

In the preliminary studies, the ratio of effervescent mixture was optimized to give floating ability to tablets within $1 \mathrm{~min}$ and for more than $12 \mathrm{~h}$ (not shown in the manuscript). Among the different viscosity grades of HPMC, K15M was selected as sustained release polymer and the concentrations were selected in a way to avoid the adverse effect on floating ability. Figure 1 explains the drug release pattern from F1 to F5 formulations and Figure 2 shows the comparison between F3 floating compression coated mini-tablets and immediate release core mini-tablets. Among the all formulations, F3 formulation was selected as the best formulation based on the drug release and floating property and used for further in vivo studies. By applying various release order kinetics to dissolution data, all the tablet formulations were shown zero order release with non-fickian diffusion, super case-II. Other model independent parameters derived from dissolution data, such as DE, MDT, T50\% and T80\% values were calculated and they revealed that the drug release was in a sustained manner (Table 5).

\section{Stability studies}

Stability studies results of F3 floating compression coated minitablets were given in Table 6 . These studies revealed that the in vitro dissolution profile and drug assay have not shown any significant difference $(\mathrm{P}<0.05)$ between before and after storage of the same formulation. The similarity factor ( $\mathrm{f} 2$ ) was found to be 85.54 between dissolution profiles of F3 tablets before and after storage of 6 months.

\begin{tabular}{|c|c|c|c|c|}
\hline Formulation & Weight variation $^{\text {** }}(\mathrm{mg})$ & Hardness ${ }^{*}\left(\mathrm{~kg} / \mathrm{cm}^{2}\right)$ & Friability (\%) & Drug content $(\%)$ \\
\hline F1 & $180.32 \pm 2.45$ & $5.1 \pm 0.56$ & 0.42 & $99.92 \pm 1.26$ \\
\hline $\mathrm{F} 2$ & $181.04 \pm 2.78$ & $4.9 \pm 0.48$ & 0.52 & $99.43 \pm 1.41$ \\
\hline F3 & $180.32 \pm 2.92$ & $5.0 \pm 0.71$ & 0.46 & $100.01 \pm 1.32$ \\
\hline $\mathrm{F} 4$ & $179.95 \pm 2.81$ & $4.9 \pm 0.64$ & 0.49 & $99.71 \pm 1.64$ \\
\hline F5 & $181.12 \pm 2.74$ & $5.1 \pm 0.82$ & 0.44 & $100.38 \pm 1.57$ \\
\hline
\end{tabular}

"Data represents mean $\pm S D(n=3)$; " Data represents mean \pm SD $(n=20)$

Table 3: Tabletting parameters of KTM floating compression coated mini-tablets.

\begin{tabular}{|c|c|c|c|}
\hline Formulation & Floating lag time (s) & Total floating time (h) \\
\hline F1 & 26 & 17.4 & 16.3 \\
\hline F2 & 29 & 13.9 & \\
\hline F3 & 28 & 12.1 & \\
\hline F4 & 34 & 11.2 & 109 \\
\hline F5 & 37 & 116 & \\
\hline
\end{tabular}

Table 4: Evaluation of KTM floating compression coated mini-tablets.

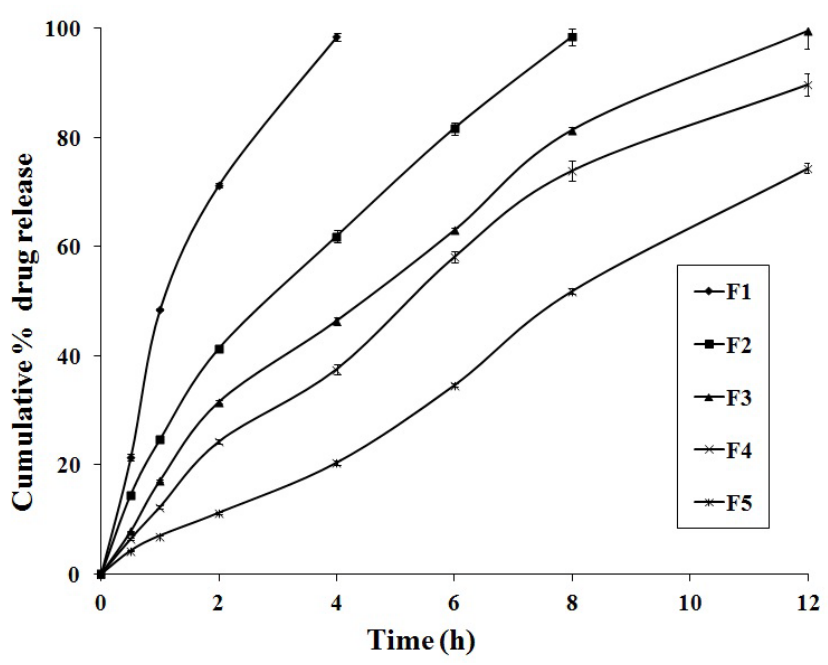

Figure 1: In vitro drug release profile of KTM floating compression coated mini-tablets $(n=6)$.

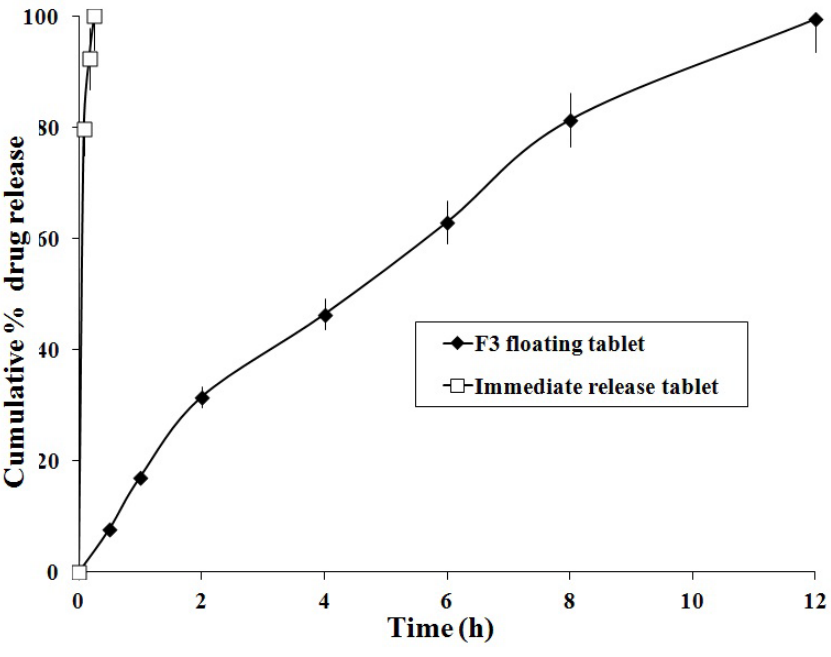

Figure 2: Release profile of KTM floating compression coated mini-tablets F3 and core mini-tablets $(n=6)$. 
Citation: Vemula SK, Venisetty RK, Veerareddy PR (2017) Formulation and Pharmacokinetics of Ketorolac Tromethamine Floating Compression Coated Mini-Tablets. J Bioequiv Availab 9: 493-498. doi: 10.4172/jbb.1000351

\begin{tabular}{|c|c|c|c|c|c|c|c|c|c|}
\hline Formulation Code & Zero order $\left(\mathbf{R}^{2}\right)$ & First order $\left(\mathbf{R}^{2}\right)$ & Higuchi ( $\left.\mathbf{R}^{2}\right)$ & Koresmeyer \& Peppas $\left(\mathbf{R}^{2}\right)$ & Peppas (n) & MDT (h) & DE (\%) & T50\% (h) & $\mathrm{T} 80 \%(\mathrm{~h})$ \\
\hline $\mathrm{F} 1$ & 0.982 & 0.832 & 0.968 & 0.927 & 0.62 & 1.44 & 63.12 & 1.1 & 2.6 \\
\hline $\mathrm{F} 2$ & 0.987 & 0.851 & 0.963 & 0.936 & 0.67 & 3.19 & 59.15 & 2.8 & 5.8 \\
\hline F3 & 0.989 & 0.834 & 0.972 & 0.931 & 0.71 & 4.70 & 60.48 & 4.4 & 7.8 \\
\hline $\mathrm{F} 4$ & 0.971 & 0.853 & 0.968 & 0.921 & 0.64 & 4.85 & 53.47 & 5.2 & 9.4 \\
\hline F5 & 0.982 & 0.812 & 0.970 & 0.924 & 0.69 & 6.10 & 36.56 & 7.7 & 12.6 \\
\hline
\end{tabular}

$\mathrm{R}^{2}$ : Correlation coefficient; $\mathrm{n}$ : Diffusional exponent; MDT: Mean Dissolution Time; DE: Dissolution Efficiency; T50\%: Time to release $50 \%$ drug release; T80\%: Time to release $80 \%$ drug release

Table 5: Release kinetics and dissolution parameters of KTM floating compression coated mini-tablets.

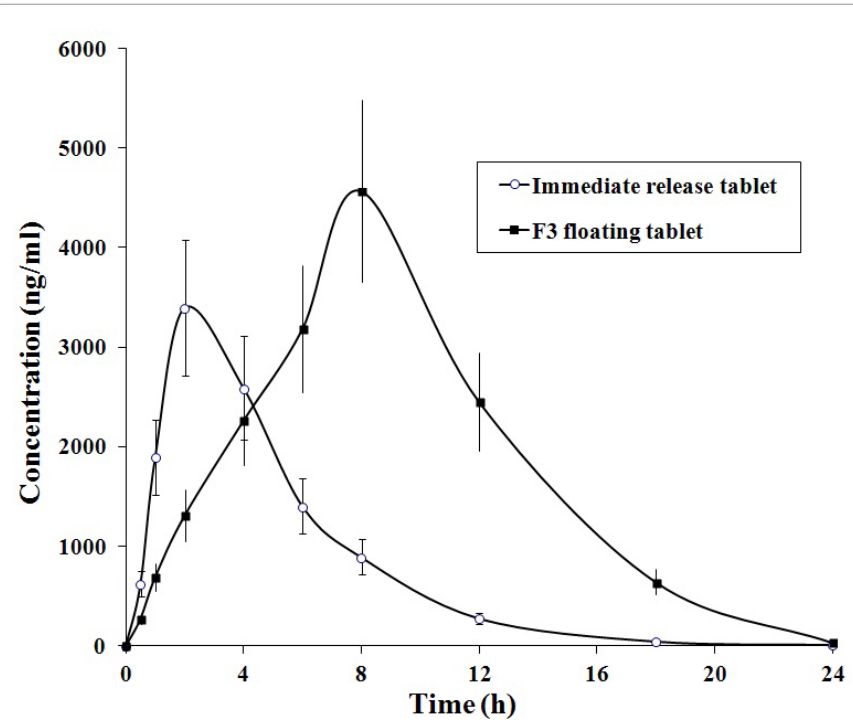

Figure 3: Time versus mean plasma concentration profiles of KTM following the oral administration of floating compression coated mini-tablets F3 and immediate release core mini-tablets $(n=12)$.

\begin{tabular}{|c|c|c|c|c|}
\hline Time (h) & Before storage & After $\mathbf{6}$ months & $\begin{array}{c}\boldsymbol{t} \text {-test at 0.05 } \\
\text { LS }\end{array}$ & $\begin{array}{c}\text { Similarity } \\
\text { Factor }\left(\boldsymbol{f}_{\mathbf{2}}\right)\end{array}$ \\
\hline 0 & $0.00 \pm 0.00$ & $0.00 \pm 0.00$ & \multirow{2}{*}{ Not Significant } & 85.54 \\
\cline { 1 - 3 } 0.5 & $7.82 \pm 0.42$ & $7.14 \pm 0.51$ & & \\
\hline 1 & $17.15 \pm 0.67$ & $16.43 \pm 0.32$ & & \\
\hline 2 & $31.54 \pm 0.98$ & $30.26 \pm 0.48$ & & \\
\hline 4 & $46.39 \pm 0.45$ & $44.92 \pm 0.56$ & & \\
\hline 6 & $62.98 \pm 0.86$ & $61.54 \pm 0.87$ & & \\
\hline 8 & $81.34 \pm 0.82$ & $79.81 \pm 0.91$ & & \\
\hline 12 & $99.46 \pm 0.93$ & $98.06 \pm 0.78$ & & \multirow{2}{*}{ Not Significant } \\
\cline { 1 - 3 } \% Assay & $100.01 \pm 1.32$ & $99.61 \pm 1.53$ & \\
\hline
\end{tabular}

Table 6: Stability studies of KTM floating compression coated mini-tablets F3.

\section{Pharmacokinetics in healthy volunteers}

All the useful and possible pharmacokinetic parameters were determined for $\mathrm{F} 3$ floating tablets in comparison to immediate release core mini-tablets. KTM plasma concentrations comparison between immediate release and floating tablets were shown in Figure 3. All the calculated mean pharmacokinetic parameters were given in Table 7.

\section{In vitro-in vivo correlation (IVIVC)}

IVIVC was carried out for F3 floating tablets using in vitro cumulative percent drug release (X-axis) and cumulative AUC obtained after oral administration (Y-axis). From the obtained graph, correlation coefficient ( $\mathrm{r} 2)$ was found to be 0.9302 that indicates the good correlation between the in vitro and in vivo parameters (Figure 4).

\begin{tabular}{|c|c|c|c|}
\hline Parameters & F3 Floating tablets & Immediate release tablets & $\mathbf{P}<0.05$ \\
\hline $\mathrm{C} \max (\mathrm{ng} / \mathrm{ml})$ & $4566.23 \pm 28.17$ & $3396.47 \pm 25.83$ & 0.05 \\
\hline $\mathrm{T} \max (\mathrm{h})$ & $8.00 \pm 0.01$ & $2.00 \pm 0.01$ & 0.05 \\
\hline $\mathrm{AUC}_{0 .-\mathrm{o}}(\mathrm{ng}-\mathrm{h} / \mathrm{ml})$ & $43028.91 \pm 71.58$ & $19194.07 \pm 62.34$ & 0.05 \\
\hline $\mathrm{MRT}(\mathrm{h})$ & $8.83 \pm 0.02$ & $4.86 \pm 0.02$ & 0.05 \\
\hline Relative bioavailability: AUC of F3 tab/AUC of Conventional tab $=2.242$ \\
\hline
\end{tabular}

Table 7: Pharmacokinetics of KTM floating compression coated mini-tablets and immediate release core mini-tablets.

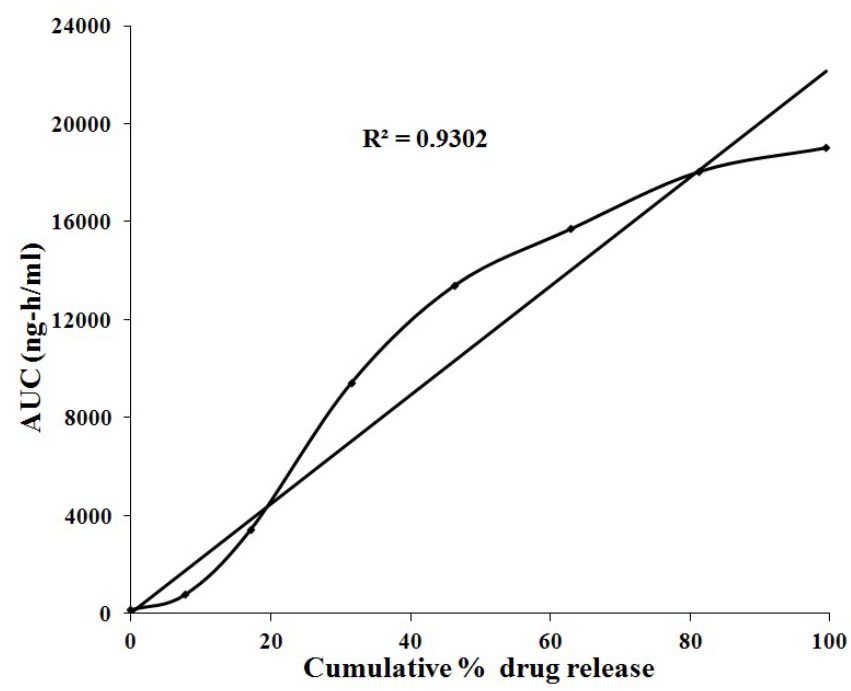

Figure 4: In vitro-in vivo correlation plot of KTM floating compression coated mini-tablets F3.

\section{Discussion}

Formulation of floating tablets with acceptable tabletting properties and desired prolonged release without adverse effect on floating ability is a big challenge to the formulation scientists. In the present study, an attempt was made to solve this problem by compression coating of mini-tablets. The prepared floating mini-tablets were characterized for different physical properties such as weight variation, hardness friability and drug content to check the compliance with pharmacopoeial standards and they were found to be uniform. Evaluation of weight variation and drug content indicates the uniformity in drug dose and total tablet weight and determination of hardness and friability denotes the tablets strength and mechanical integrity.

Besides the above tabletting parameters, the floating tablets were also evaluated for floating lag time, total floating time and \% swelling index. Floating lag time and total floating time depend highly on the amount of effervescent mixture incorporated in the tablet. $30 \mathrm{mg}$ of sodium bicarbonate is optimized to give make the tablets float in less 
than $40 \mathrm{sec}$. It was clearly observed that the increase in the concentration of HPMC K15M, the floating lag time was increased. Similar type of results in floating behaviour was observed in clarithromycin floating tablets using various grades of HPMC [25]. Among the all formulations, F5 formulation was shown maximum swelling index due to high concentration of HPMC K15M. Similar type of results in swelling index was observed in a study developed by Pawar et al. [26].

From the preliminary studies, the suitable HPMC grade for compression coating was selected. Different formulations were prepared and evaluated for drug release using various grades of HPMC and from the dissolution studies, HPMC K15M was selected as the compression coating polymer to provide the desirable prolonged drug release. The swelling index of HPMC K15M was showed higher value than lower grades but less than K100M. Among the different HPMC viscosity grades, HPMC K15M was superior in the swelling, compressibility and mechanical integrity. Similar type or results were observed with ketorolac tromethamine colon targeted compression coated tablets developed by Vemula and Veerareddy [17].

After the in vitro dissolution studies and floating studies of preliminary formulations, final ratio of core mini-tablets and sodium bicarbonate was set to 2:1. This set of composition was shown not only optimized floatation but also the desired sustained drug release that depends on HPMC concentration. From the in vitro dissolution studies of F1 to F5 formulations, as the HPMC K15M increased, the more sustained release was observed due to increase in swelling index. In the present study, the F3 formulation is incorporated with $30 \mathrm{mg}$ of HPMC $\mathrm{K} 15 \mathrm{M}$ was able to produce $99.46 \pm 0.93 \%$ drug release in $12 \mathrm{~h}$ with significant floating capacity. Hence F3 formulation was considered as the best formulation and used for further evaluations in this study.

The results of different kinetic models revealed that they followed zero order release as it was shown high correlation coefficient values. The $\mathrm{n}$ values from Peppas model indicated supercase-II transport. Results of DE, MDT, T50\% and T80\% were revealed that the drug release was in a sustained manner as the HPMC K15M concentration was increased. From the stability studies, after storage of six months, F3 tablets were shown no significant difference in drug release behaviour before and after storage. The similarity factor (f2) was found to be 85.54 between dissolution profiles of F3 tablets before and after storage.

Possible pharmacokinetic parameters were estimated for F3 floating compression coated mini-tablets and compared with immediate release core mini-tablets. Above results were shown in Table 7 and when observed those results, it is clear indication that the change in $\mathrm{C}_{\max }$ and shift in $\mathrm{T}_{\max }$ are the evidence of sustained drug release of F3 tablets. This may be due to fast disintegration, dissolution and absorption of KTM from core mini-tablets, but due to presence of HPMC K15M, F3 floating tablets were shown prolonged drug release. The AUC value of F3 floating tablets was the indication of 2.25 -fold increase in bioavailability when compared to immediate release core mini-tablets. MRT value indicating long resident time of floating compression coated tablets. Applying of statistical analysis to above pharmacokinetic parameters was revealed that there was a significant difference in the $\mathrm{C}_{\max }, \mathrm{T}_{\max }$, AUC and MRT. IVIVC results signified the good correlation between in vitro and in vivo parameters. Hence, development of floating compression coated mini-tablets is a suitable approach to enhance the bioavailability and reduce the irritant effect on stomach of KTM (Supplementary Files 1 and 2).

\section{Conclusion}

This research was planned to design and develop the floating tablets using compression coating of HPMC K 15M and effervescent mixture on the KTM core mini-tablets. Incorporation of $30 \mathrm{mg}$ of sodium bicarbonate was able to float the prepared compression coated mini-tablets for $12 \mathrm{~h}$. From the various evaluation tests, F3 formulation was considered as the best formulation to give the desired prolonged drug release. Calculated pharmacokinetic parameters were proved the increase in bioavailability of F3 tablets in comparison to core minitablets.

\section{Acknowledgements}

The authors acknowledge the AICTE, New Delhi for granting this project under RPS scheme (20/AICTE/RIFD/RPS (POLICY-III) 145/2012-13). The authors also thank to Management, Chaitanya College of Pharmacy Education and Research for providing facilities.

\section{References}

1. Alexander S, Juergen S (2006) Gastroretentive drug delivery systems. Expert Opin Drug Del 3: 217-233.

2. Gangadharappa HV, Pramod Kumar TM, Shiva Kumar HG (2007) Gastric floating drug delivery systems. Ind J Pharm Educ Res 41: 295-306.

3. Ishak RAH, Awad GAS, Mortada ND, Nour SAK (2001) Preparation, in vitro and in vivo evaluation of stomach-specific metronidazole-loaded alginate beads as local anti- Helicobacter pylori therapy. J Control Rel 119: 207-214

4. Christian V, Ghedia T, Gajjar V (2011) A review on floating drug delivery system as a part of GRDDS. Int J Pharm Res Dev 3: 233-241.

5. Vemula SK (2015) Formulation and pharmacokinetics of colon-specific doublecompression coated mini-tablets: chronopharmaceutical delivery of ketorolac tromethamine. Int J Pharm 491: 35-41.

6. Vemula SK (2015) A novel approach to flurbiprofen pulsatile colonic release: formulation and pharmacokinetics of double-compression-coated mini-tablets AAPS PharmSciTech 16: 1465-1473.

7. El-Zahaby SA, Kassem AA, El-Kamel AH (2014) Design and evaluation of gastroretentive levofloxacin floating mini-tablets-in-capsule system for eradication of Helicobacter pylori. Saudi Pharm J 22: 570-579.

8. Roberts M, Vellucci D, Mostafa S, Miolane C, Marchaud D (2012) Development and evaluation of sustained-release Compritol 888 ATO matrix mini-tablets. Drug Del Ind Pharm 38: 1068-1076.

9. Meka L, Kesavan B, Kalamata VN, Eaga CM, Bandari S, et al. (2009) Design and evaluation of polymeric coated minitablets as multiple unit gastroretentive floating drug delivery systems for furosemide. J Pharm Sci 98: 2122-2132.

10. Lopes MC, Lobo JMS, Pinto JF (2006) Directly compressed mini matrix tablets containing ibuprofen: preparation and evaluation of sustained release. Drug Del Ind Pharm 32: 95-106.

11. Sjia-areevath J, Munday DL, Cox PJ, Khan KA (1996) Release characteristics of diclofenac sodium from encapsulated natural gum mini-matrix formulations. Int J Pharm 139: 53-62.

12. Vemula SK, Veerareddy PR, Devadasu VR (2014) Pharmacokinetics of ketorolac tromethamine compression-coated tablets for colon delivery. Drug Del Trans Res 4: 310-319.

13. Padma V, Subhash P, Sunil V (2000) HPTLC determination of ketorolac tromethamine. J Pharm Biomed Anal 22: 679-683.

14. Thanoo B, Sunny M, Jayakrishnana A (1993) Oral sustained release drug delivery systems using polycarbonate microspheres capable of floating on gastric fluid. J Pharm Pharmacol 45: 21-24.

15. Abou el Ela AESF, Hassan MA, El-Maraghy DA (2014) Ketorolac tromethamine floating beads for oral application: Characterization and in vitrolin vivo evaluation. Saudi Pharm J 22: 349-359.

16. Veerareddy PR, Vemula SK (2012) Formulation, evaluation and pharmacokinetics of colon targeted pulsatile system of flurbiprofen. J Drug Targ 20: 703-714.

17. Vemula SK, Veerareddy PR (2013) Development, evaluation and 
Citation: Vemula SK, Venisetty RK, Veerareddy PR (2017) Formulation and Pharmacokinetics of Ketorolac Tromethamine Floating Compression Coated Mini-Tablets. J Bioequiv Availab 9: 493-498. doi: 10.4172/jbb.1000351

pharmacokinetics of time- dependent ketorolac tromethamine tablets. Exp Opin Drug Del 10: 33-45.

18. Rosa M, Zia H, Rhodes T (1994) Design and testing in vitro of a bioadhesive and floating drug delivery system for oral application. Int J Pharm 105: 65-70.

19. Tadros MI (2010) Controlled-release effervescent floating matrix tablets of ciprofloxacin hydrochloride: development, optimization and in vitro-in vivo evaluation in healthy human volunteers. Eur J Pharmaceut Biopharmaceut 74: 332-339.

20. Valluru R, Siddaramaiah T, Pramod M (2008) Influence of natural polymer coating on novel colon targeting drug delivery system. J Mater Sci 19: 21312136.

21. Talukder RM, Fassihi R (2008) Development and in-vitro evaluation of a colonspecific controlled release drug delivery system. J Pharm Pharmacol 60: 12971303.
22. Chaudhary A, Tiwari N, Jain V, Singh R (2011) Microporous bilayer osmotic tablet for colon-specific delivery. Eur J Pharm Biopharm 78: 134-140.

23. Mathews BR (1999) Regulatory aspects of stability testing in Europe. Drug Dev Ind Pharm 25: 831-856.

24. Vemula SK, Katkum R (2015) Colon-specific double-compression coated pulsatile tablets of ketorolac tromethamine: formulation development and pharmacokinetics. J Drug Del Sci Tech 29: 78-83.

25. Ugurlu T, Karacicek U, Rayaman E (2014) Optimization and evaluation of clarithromycin floating tablets using experimental mixture design. Acta Poloniae Pharmaceutica Drug Res 71: 311-321.

26. Pawar HA, Gharat PR, Dhavale RV, Joshi PR, Rakshit PP (2013) Development and evaluation of gastroretentive floating tablets of an antihypertensive drug using hydrogenated cottonseed oil. ISRN Pharmaceutics. 